\title{
Building Strategic Resource - A Factor for the Competitive Advantages of the Construction Firm
}

\author{
Aneta Marichova* \\ Department of Social Sciences, University of Architecture, Civil Engineering and Geodesy, Bulgaria
}

Submission: May 20, 2018; Published: June 27, 2018

*Corresponding author: Aneta Marichova, Department of Social Sciences, University of Architecture, Civil Engineering and Geodesy, Sofia, Bulgaria, Email: aneta.marichova@abv.bg

Abstract

In the new dynamic conditions, growing competition, dramatic changes in demand, the main problem for the construction company is: what are its possibilities for creating a strategic resource to ensure the successful long-term development and positioning. The strategic resource is created and developed not only by the operational capabilities of the company, but also by the efficient organization and management of the company, its market position and the growth potential, i.e. dynamic capabilities. The aim of the study was to determine the characteristics of the strategic resource as a factor for competitive advantages and on this basis to analyze and evaluate of the activity of four construction companies operating on different market segments - two of them on the building market and two civilian market constructions.

Keywords: Competitive advantages; Construction firm; Construction market; Dynamic capabilities; Firm competencies; Functional Competencies (Operational capabilities); Strategic Resource (VRIO --value, rarity, imitability, organization)

\section{Introduction}

General characteristic of the construction market is:

a. In this market are too many, mostly small businesses,

b. They have no strategy and are willing to work anything to have jobs or have more work,

c. Specific characteristics of a product that combines the characteristics of goods and services and

d. The specific characteristics of the construction market and construction process,

e. Higher share of labor-intensive production, relatively low labor productivity.

A relatively low share of the added value created and low propensity to invest. Construction firm usually focuses on efficacy of individual projects rather than long-term strategies. Moreover, the construction market has a high sensitivity to the client's price, which creates restrictions actions and the ability to differentiate the company by product. This situation supports the strategy of flexibility and a low degree of specialization. The longer duration of the investment and the production process in the industry, which slow the pace of economic growth, raises the problem of reducing the time of construction. This means above all the need for rapid industrialization and the introduction of new, advanced technologies. These are serious challenges for most construction companies, which are mainly small or medium, which means relatively limited technological, market, financial and innovation capabilities. This poses each company to complex problem: what are the possibilities for creating a strategic resource that it can ensure the successful long-term development and positioning. The aim of the study is:

i. Identify the characteristics of strategic resource as a factor of competitive advantage, and

ii. To develop and implement a model for creating a strategic resource that provides competitive advantages for the construction firm.

\section{The Theoretical Framework of the Study}

This chapter will identify the characteristics of strategic resource as a factor of competitive advantage and will develop a model for creating and maintaining a strategic resource meets the following characteristics and providing the realization of competitive advantages.

The company's resources are defined as "all assets, capabilities, organizational processes, firm attributes, information, knowledge, which are controlled by it and allowing it to implement strategies that are not met by current and potential competitors" [1]. Fundamental basis for the creation of a strategic asset in firm [2] not only need to have the possession of specific resources, but the need for distinctive capabilities and a specific mechanism for their combination and use, providing realization of business objectives. 


\section{Civil Engineering Research Journal}

Not all resources are strategic assets or critical resources [3], but only those who identify and develop distinctive competence of the company. Distinctive competencies of the company are "related to the collective knowledge of the organization, coordination skills to produce products and integration of different technological levels" [4]. In the resource-based theory that is associated with the possibilities firm to create a resource that meets the four characteristics - value, rarity, difficult to imitate (imitability) and without substitutes (no substitute) (VRIN-frame). Resourcebased theory is developed on the idea that every company has different resources, different arrangements that define its specific VRIO (value, rarity, imitability, organization) - framework that is a factor for the realization of sustainable competitive advantage.

In a dynamic external environment, the company must build up a system of opportunities that ensure effective change and reconfiguration of internal resources and competencies. These business opportunities related to changes in the business environment and its adaptation to them are defined as "dynamic capabilities" [5], that factor in building strategic resource (VRIO) and competitive advantage.

The author defines dynamic capabilities as a complex, multidimensional structure of interrelated and complementary specific activities in the firm which include its ability to identify and analyze the need for changes, to develop its own system of solutions for the reconfiguration of functional competencies in response to changes in the external and internal environment and to apply the necessary actions purpose of adapting to them. The company's ability to monitor changesin the external environment,to assess opportunities and threats to develop andlearning (absorption, assimilation, use of new knowledge) are defined as dynamic capabilities of second level. They are directly related to the dynamics of the environment in which it operatesare a function of the senior management team. The ability of the company to implement a process of integrating, coordinating, and reconfiguring internal resources is defined as dynamic capabilities of first level. They are linked to the internal organization and are developed by expanding and improving managerial capabilities. Dynamic capabilities of second level affect dynamic capabilities of first level and reconfigure business competencies to respond to changes in the external environment.

Functional competences (market, technology, innovation, organizational and managerial competencies) are defined as zero-order opportunities that ensure the company's operational efficiency. They have common characteristics but specific conditions of application (as a result of the development dynamic capabilities of second and first level), which can only provide effective organization and realization of the company goals.

The relationship between different levels of dynamic capabilities is accomplished through complex transformation mechanisms, converting, changing opportunities from a lower order into higher order options, and vice versa. Dynamic capabilities of second and first level help the company expand, change, and reconfigure its existing functional competencies into new, which better respond to changes in the environment and provide more efficient use of existing resources. Therefore, each component of dynamic capabilities is different, unique, and offers a specific way to reconfigure functional competencies and create new ones. The mechanism through which to integrate knowledge, skills and create new competences, develops and creates new strategic opportunities and resources. They are mainly related to the development of intangible assets-learning in the organization andin particular, solving the problemto better coordinate different product skills and integrate the flow of technological knowledge.

Dynamic capabilities have no direct, but an indirect link with the realization of competitive advantages and performance. They are above all, organizational capabilities that can provide competitive advantages (including long-term) of the company, with one basic requirement: to apply earlier, more perceptive and more effective than managers. Their role is related to a change in functional competencies and the existing resource base, which changes the final production result and the position of the company in response to changes in the environment and ensures the building of competitive advantages for the company. Therefore, functional competencies have a role as a mediator between dynamic capabilities and performance.

Dynamic capabilities have value for the company only if they are created strategic resource that maintains and increases its advantages over competitors - current and potential. The goal of any firm is to build a dynamic capabilities and on this basis, creating a unique and difficult to imitate resources - VRIO, as a major factor in realizing competitive advantages and performance and which must comply with the following characteristics [6]:

a. The resource has a high value if the company has the ability to monitor changes in the external environment, to assess the opportunities and threats to development, learning and absorption, assimilation, use of new knowledge, i.e. building dynamic capabilities of the second level. This allows the firm to make effective use of changes in the external environment and develop your product or service in any part of the creation of value chain and establish that a particular part of this chain creates a higher value than the next best competitor.

b. The resource is difficult to imitation, when the firm carried out a process of integration, coordination, and reconfiguration, i.e. building dynamic capabilities of first level under the influence of the dynamic capabilities of the second level. The mechanism by which integrate knowledge, skills and creating new skills is unique specific to each company. The competitive firms are discouraged and continue to work on the famous novel way can not find another good enough new way of solving a problem and put up with lower profits.

c. The resource is unique because it built dynamic capabilities of first and second level help the company to 
expand, modify and reconfigure its existing operational capabilities or functional competencies in new ones which respond better to changes in the environment. The relationship between different levels of dynamic capabilities is carried out through complex and specific to each company transformation mechanisms that transform and develop dynamic capabilities of lower-order in capabilities of higherorder and back.

d. The organization of the company allows the use of valuable, rarity and difficult to imitate resources because they lack the necessary firm competencies and management skills for effective transformation of resources into the desired end result, and there is an effective system for customer feedback and opportunities for continuous improvement their service, effective management and control of bottom-up, which includes budgeting and reporting activities throughout the hierarchical corporate organization, an effective system for stimulating human resources, which includes cash and noncash incentives and quality control.

e. The general conclusion that sustainable competitive advantage is a function of the simultaneous execution of the four characteristics of the company's resources and only this combination provides the realization of company goals - higher profit compared with the average in the industry. Characteristics of strategic resources suggest that it can be created in two ways: to be proprietary and integrated in a single company or be established with the participation of companies in the vertical supply chain.

These theoretical formulations can be summarized in the following model: "Firm Resources and Competencies - Strategic Resource (VRIO) - Competitive Advantages and Performance" (Figure 1) and the definition of these hypotheses will be tested in the empirical study:

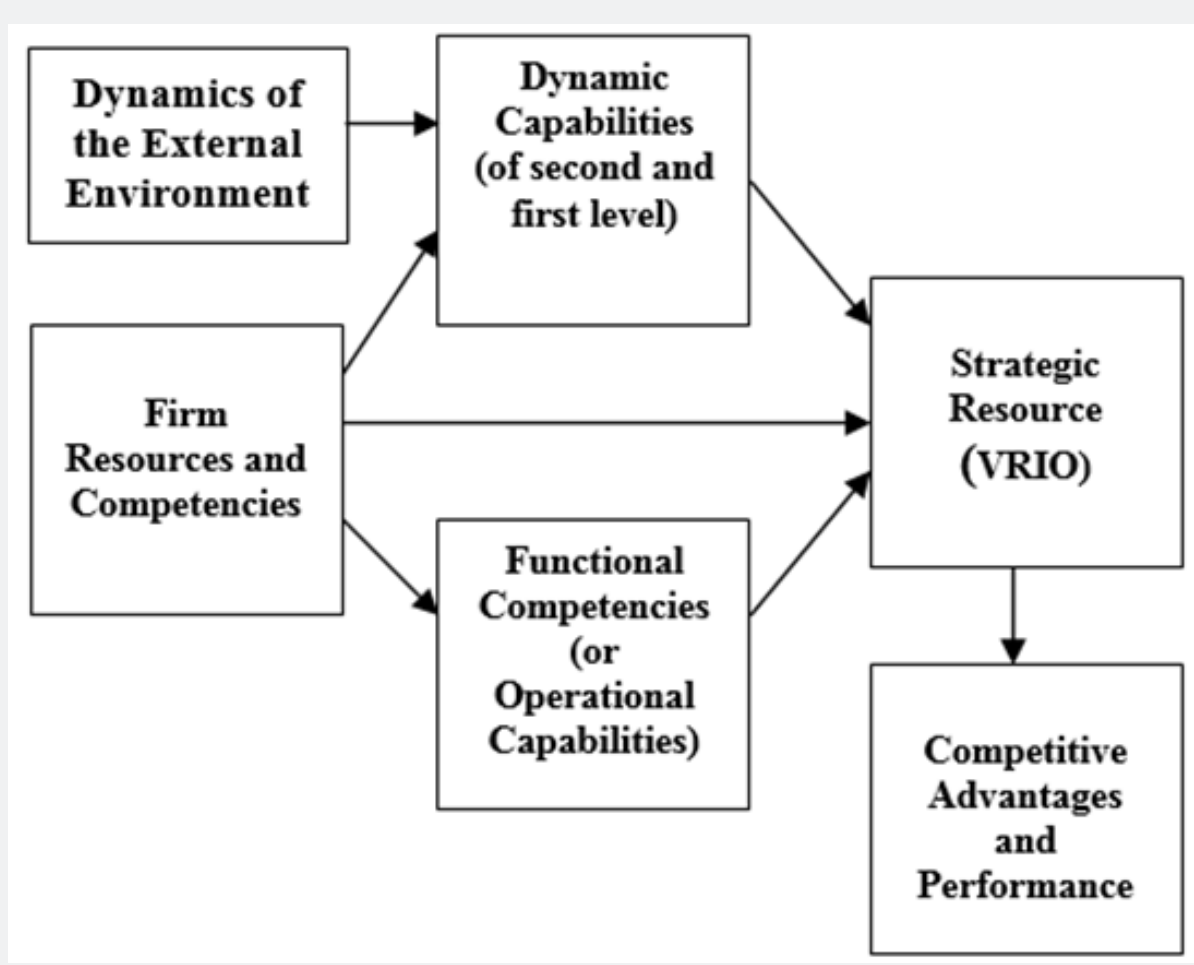

Figure 1: Firm Resources and Competencies - Strategic Resource (VRIO) - Competitive Advantages and Performance.

Hypothesis 1: The development of firm resources and competencies have a strong positive impact on the building strategic resource (VRIO).

Hypothesis 1a: Dynamic capabilities (of second and first level) have a positive influence on the building strategic resource (VRIO) in the firm.

Hypothesis 1b: The functional competencies (or operational capabilities) have rights regarding the building strategic resource (VRIO) in the firm.
Hypothesis 2: The established strategic resource (VRIO) has a strong positive impact on the realization of competitive advantage and performance.

\section{Application of Theoretical Framework and Hypothesis Testing}

In this chapter of the study, the developed model is applied to analysis and evaluation of the strategic resource, created in four construction companies, working on the construction market in Bulgaria and will be tested two hypotheses. This study is exploratory, seeking evidence of the ability of a construction 


\section{Civil Engineering Research Journal}

company to establish and maintain strategic assets in order to create competitive advantage and corporate goals.

\section{The experimental method and restrictive conditions}

Companies that have been studied are included in "top 20" of the construction market in Bulgaria and working various market segments. Two of them are market leaders in civil engineering, and the other two are working and have a leading position in the market of building construction. Surveyed companies have varying degrees of diversification or specialization in the relevant market segment, a different range of activities (considered as a three-stream supply of raw materials, design and construction), different story, different spatial localization, a different business model. They are selected on the basis of two criteria:

a. They have a system as a strategic resource that is used effectively to realize the company's goals, to adapt to the external environment and created a business model that provides a lean organization, management and continuous accumulation of knowledge and experience in people and the company.

b. Resources are mobile and all companies have similar resources, but only given company has an asset resulting from a unique combination and organization of its internal resources, which offset the impact of external forces and successfully positioned the defined market or market segment or niche. The selected firms have different strategies, because they have different operational capabilities related to production, different dynamic capabilities related to the organization and management of the company, different market positioning and other growth opportunities.

Exploring the possibilities of the construction company to create a competitive advantage and performance by building Strategic Resource (VRIO) is made on analysis and evaluation of data collected from seminars, shared opinions, evaluations, experience of managers and employees in these companies, interviews, publications in specialized journals and financial statements of companies.

Collected and processed information allows an evaluation of the company's competence (unity of dynamic capabilities and operational capabilities) in the construction company and their strong positive connection with the establishment of a strategic resource of the firm (first hypothesis), the following indicators:

i. Dynamic capabilities (hypothesis 1a) were evaluated on the following criteria: established system of a system of monitoring, evaluation, learning, organization, management and reconfiguration resources.

ii. The operational capabilities or functional competencies (hypothesis 1b) were evaluated by the following criteria: history, mission, product, customer, production, range, technology, costs, prices, vertical links, market, competitive structure, market share, strategic management.
The second hypothesis was tested based on the analysis and evaluation of the financial performance of companies (revenues and profits, financial and economic profitability, financial leverage, total liquidity, the possibility of self-financing, financial leverage) and their dynamics over the past five years, as a function the realized competitive advantages of firms.

\section{Main results of the study}

The applied method in the study, allow the author to make the following conclusions (in restrictive conditions): The testing of hypothesis $1 \mathrm{a}$ proves that in all surveyed firms the dynamic capabilities of the second level to develop and apply by senior management team in a specific way, depending on the organizational structure of the company, established connection with the external environment, created analytical system of procedures, management skills and perceptions. They outline new guidelines for company development and growth, a function of changes in demand and technology, which usually has one of the most complex tasks. The management team carry out permanent monitoring, scan the dynamics of the environment and processing large amounts of information, which enable the detection of opportunities for development. Identification of new opportunities for the development of the company basis of a detailed survey of the impact of macro factors market and technological developments in the local and global level. On the construction market this process involves analysis and detection of latent demand, development of technologies, as well as analysis of state and regulatory mechanisms, general economic and social changes, requirements for environmental protection and others. On the micro level, the process of monitoring involves analysis of market structure and the level of competition, possible actions and reactions of competitive behavior, relationships with suppliers, opportunities to build vertical integrated systems, investments in research, etc.

The managers estimate that only the monitoring of the external environment is not enough, as it is possible, the need for change is induced and/or internal reasons of dissatisfaction with the company's position, the current state of resources, etc. The simultaneous monitoring and evaluation of external and internal environment allows to assessment the capabilities of the company to respond to external changes with the existing potential, or by extending or creating new configurations.

On the market for civil engineering, researched firms build their dynamic capabilities of first level through effective decentralized structure and effective relationships with a large number of companies - contractors and subcontractors. Firms have high image in society, with many well-known, recognizable brand as a result of history, experience, routine. Companies develop their personnel policy for proper selection, training and development of employees, creating skills, managing work teams, for successful solving tasks. The main factor is the system of incentives and motivation for each employee with a clear strategy for development: professional development and specialization 


\section{Civil Engineering Research Journal}

for specific professional fields, as well as providing time and opportunity to improve their education and acquire higher qualifications, stimulating initiative.

Evaluation of operational capability (or functional competencies) in building strategic resource proves that the surveyed companies have large scale production, which enables economies of scale. Suppliers of raw materials are included in the complex structure of the company, and moreover it has stable longterm contracts with those who are outside, which allows realize and cash savings. The scope of activities includes - provision of materials, design, construction and investment. Companies use new, efficient, innovative technologies and development, transformation of knowledge, intangible assets that provide short term and high-quality sites. Leaderships position by constantly demonstrating innovative management in all business areas, as they do not just follow the latest trends in the construction industry and create them.

Testing of the second hypothesis suggests that firms have strong financial results, but with greater volatility of the firm with greater specialization. Economic profitability is higher than the average for the industry and the average interest rate, which is evidence of effective management decisions. There is a clear tendency to cover the liabilities and greater financial stability, opportunities to cover ongoing operations and own funding (over $50 \%$ ), which is a very good indicator of construction, taking into account its specifics.

The evaluation Strategic Resource (VRIO) as a factor for creating competitive advantages in the market of civil construction, created on the basis of the existing dynamic capabilities and operational competencies or firm competencies developed proves:

a. Both companies have a unique resource, but with a different dimension: The first company is widely diversified and creates a product for all market segments and all customers of the construction market and the full range of activities, and the second company creates highly specialized, quality product based on years of experience and achieved high market efficiency of civil construction.

b. Both companies offer high added value for its customers as a result of economies of scale and cost optimization in the new dynamic conditions.

c. Both companies have a difficult to imitate resource, as the first firm, it is based on the construction market leadership, active cross-border activities and achieved success as a result of history, experience, reputation, innovation, and for the second firm - highly specialized production of high quality in all respects in accordance with the basic principles of engineering, security, technology, efficiency, aesthetics and functionality, protection of the environment and society. d. A resource that has each of the two companies is not completely replaceable. What it does is replaceable: For the first company, strategic resource is a result on a large scale and comprehensive activity, which allows it to offer greater value to customers compared to competitors based on cost leadership, history, experience, reputation. For the second company strategic resource is developed on its ability to create unique, high quality and specialized products for the market of civil construction and unique access to classified information and building secret objects.

Therefore, we can summarize: both explored companies operating on the market of civil engineering have strategic resource that is valuable, rarity and difficult to imitate, and have the necessary organization and capacity, i.e. dynamic capabilities, allowing them to achieve sustainable competitive advantage and profit above the average for the industry/market in the long run.

On the market of building construction, the firms construct their dynamic capabilities of first level by decentralized management, which includes project managers, a separate structure associated with the development of new products, technical managers and other specialized units. Governor delegate rights management staff to achieve the objectives of quality, health and safety and the environment and requires all employees personally involved in achieving these goals. Skills and professionalism of every employee is a guarantee for the quality of the completed works. Strategic changes companies are focused on the development of intangible assets and innovation, opening new offices in different parts of the country, development of an integrated delivery system with the active participation of all actors in the construction process and the implementation of a set of activities to protect the environment.

The analysis of the operational capabilities as a factor in building strategic resource proves that the surveyed companies perform a wide range of activities in the field of building construction and real estate investments - design, development, implementation, testing, sales and property management, and production of construction materials. Firms offer unique solutions and create highly specialized product with high quality, covering all stages of production, focused on the wishes of the client.

The aim is always to their activities associated with excellent quality of service, personal commitment and loyalty to the client. For this purpose, they build long-term partnerships with its customers - large investors and households on the basis of honesty and integrity and customer feedback. Every firm tries to find the optimal solution for our clients and work so that they feel ownership of their staff to each individual project and the possibility of flexible solutions to each individual problem.

In recent years, the surveyed firms are moving to expand its activities in the guidelines relating to less investment in physical equipment, but require more intangible assets, which means 


\section{Civil Engineering Research Journal}

implementing effective, innovative technologies and development of sustainable construction. They shall endeavor to apply the latest materials and technologies in construction based on the constant transformation of knowledge, exchange of information, which ensure realization of the desired results and optimization of processes in the company [7].

Testing of the second hypothesis proves that the financial performance of both companies have exclusive depending on cyclical fluctuations. All indicators have high values during the construction boom and falling during the crisis. A relatively short time, both companies managed to overcome the negative trend and to stabilize due solely created them strategic resource that makes them identifiable, recognizable and sought partners in this market. Realized economic profitability is above the industry average and above-average rate, which is a good indicator of the profitability of the market and effectiveness of managerial strategic decisions. Companies have good opportunities to cover current operations and even provide their own funding.

The evaluation of Strategic Resource (VRIO) as a factor for creating competitive advantages in the market of building construction proves:

a. Both companies have a unique resource as a result of the created highly specialized, quality products that meet the requirements of all customers and business partners. The difference comes down to the fact that the first firm to focus on the requirements of sustainable development and preservation of national cultural and historical heritage of Bulgaria and the second firm focuses on offering unique, flexible solutions covering the entire construction process and tailored to the individual wishes of each client.

b. Both companies offer high added value to its clients related to the creation of a differentiated product that includes the optimal solution for each individual client. First company directs its activities to continuously improve the quality product offerings and efficient use of scarce resources - material, human and financial resources, according to the needs of customers, and the second company, covering the full cycle of construction and investment process aims to create additional facilities its customers.

c. Both companies have a difficult to imitate resource based on quality, personal commitment and loyalty to the client. A major factor in the first firm is people with their experience, innovation, striving for personal improvement, which develops the capacity of the company. In the second firm relies on tradition and experience combined with high reputation and strong market positions.

d. A resource that has each of the two firms is not completely replaceable. What makes replaceable for first company is the result of partnerships with all customers and the increased role and importance the company attaches to human resources, which has its efforts on its ongoing development and motivation, and for the second firm uniqueness resource is the result of history, experience, reputation and a wide range of activities [8].

We can summarize: both explored firms operating in the market of building construction have a strategic resource that is valuable, rarity and difficult to imitate, and have the necessary organization and capacity, i.e. dynamic capabilities, allowing them to achieve sustainable competitive advantage and profit above the average for the industry/market in the long run, as evidenced by the analysis of the financial data of companies (second hypothesis).

\section{Conclusion}

To analyze and evaluate the capabilities of the construction company to create a strategic resource as a factor to create competitive advantages, the author applied a conceptual model "Firm Resource and Competencies - Strategic Resource (VRIO) - Competitive Advantages and Performance". The author explores the activities of several companies working on a different market (civil and building construction market), offering different products to different customers. The selection of companies was made on the basis of two criteria: to have a strategy and that a different strategy. Basis for analysis and testing of the model, defined hypotheses and the conclusions is collected information for operational capabilities and dynamic capabilities, or firm competencies, financial data and strategic changes in order to adapt to the dynamics of the external environment. In their study proved:

a. On the market for civil engineering, rarity and high value resource for first firm is created on the basis of a broad and diversified product offered to all market segments, for all customers in the construction market and a full range of business, or (for the second company) highly specialized, quality product available in the market for civil engineering. Created a strategic resource in the two firms is the result of years of experience and achieved high efficiency. What makes resource companies difficult imitation and substitution is the development of dynamic capabilities - efficient organization, management, history, experience, reputation, innovation intangible asset - people, knowledge and systems.

b. On the market for building construction rarity and high value firm resources associated with the creation of a differentiated product that includes the optimal solution for each individual client. First company directs its activities to continuously improve the quality product offerings and efficient use of scare resources, according to the needs of customers, and the second company, covering the full cycle of construction and investment process aims to create additional facilities its customers by offering unique, flexible solutions tailored to the individual wishes of each client.

Both companies have a difficult to imitate and substitute resources, because it is based on quality, personal commitment and loyalty to the client. A major factor in the first company is 
people with their experience, innovation, striving for personal improvement, which develops the capacity of the company. The second firm relies on tradition and experience combined with high reputation and strong market positions.

Analysis and evaluation of Strategic Resource (VRIO) as a factor for creating competitive advantages in the selected firms is a "snapshot" capabilities, internal resources of the company, its ability to be the most effective organization and management combination that makes this resource unique strategic and determines the capabilities of the company to realize competitive advantages at given external conditions. Long-term success of any company depends on its ability to carry three permanent actions: monitoring the external environment, assessment of development opportunities (strengths and weaknesses of the company, compared with the next best competitor) and making decisions to change the resource in order to adjust, to adapt to the dynamic external environment.

In the study, the author used a comparative method that allows to identify the strengths and weaknesses of the surveyed companies and to develop a successful manufacturing strategy on thorough analysis of the characteristics of the company's strategic resource. In the civil construction market, companies can create strategic resources and realize a competitive advantage through the process of developing operational capabilities and dynamic capabilities. In the building construction market, companies can create a strategic resource and realize a competitive advantage through the process of differentiation and product development, and building effective customer relationships. The author demonstrates a practical point of view, the creation of own strategic resource other than the competitor, other than its competitive area may be the result solely of different thinking, different combination and recombination of firm competencies in response to the dynamics of external environment. Competitive advantage and performance are a function of the skills for organization and management of the company in a way that allows the creation of unique value, specific to a given company resource.

\section{References}

1. Barney J (1991) Firm resources and sustainable competitive advantage. Journal of Management 17(1): 99-120.

2. Barney J, Clark D (2001) RBV of competitive advantage. Journal of management 7: 643-650.

3. Peteraf M (1993) The Cornerstones of Competitive Advantage: A Resource-Based View. Strategic Management Journal 14(3): 179-191.

4. Flanagan R, Lu W, Shen L, Jewell C (2007) Competitiveness in construction: a critical review of research. Construction Management and Economics 25(9): 989-1000.

5. Prahalad C, Hamel G (1990) The Core Competence of the Corporation. Harvard Business Review 68(3): 79-91.

6. Teece D, Pisano G, Shuen A (1997) Dynamic capabilities and strategy management. Strategic management Journal 18(7): 509-533.

7. Helfat C, Finkelstein S, Mitchell W, Peteraf M, Singh H, et al. (2007) Dynamic capabilities: Foundations. In Dynamic Capabilities: Understanding Strategic Change in Organizations. London: Blackwell Publishing.

8. Barney J, Hesterly W (2005) Strategic management and Competitive advantage, Concepts. Pearson Education. Inc. Upper Saddle River. New Jersey, USA.

\section{Your next submission with Juniper Publishers will reach you the below assets}

- Quality Editorial service

- Swift Peer Review

- Reprints availability

- E-prints Service

- Manuscript Podcast for convenient understanding

- Global attainment for your research

- Manuscript accessibility in different formats

( Pdf, E-pub, Full Text, Audio)

- Unceasing customer service

Track the below URL for one-step submission https://juniperpublishers.com/online-submission.php 